Wawasan:

Jurnal Kediklatan Balai Diklat Keagamaan Jakarta

PISSN: 2548-9232; ${ }_{\mathrm{E}}$ ISSN: 2775-3573

Volume 2 Nomor 1 Tahun 2021: 32-39

\title{
MERETAS MOTIVASI BELAJAR PESERTA DIDIK DI ERA PANDEMI MELALUI VIDEO VIRTUAL LABORATORY
}

\author{
Wahyuni Budi Hastuti \\ Balai Diklat Keagamaan Jakarta, Indonesia \\ email:yunifayuka@gmail.com
}

\begin{abstract}
Students' lack of enthusiasm in learning science-physics online during a pandemic requires the writer to look for small breakthroughs in the learning process of Dynamic Electricity material. PhET (Physical Education Technology) can be used as an alternative virtual media to guide students to learn science concepts hands-on and mind-on with enthusiasm. This article is a resume of a learning test using a virtual laboratory on dynamic electricity material for MTsN science subjects. The learning test aims to see the motivation of students towards learning and measure their learning outcomes. In this case study, observation, interview, and test techniques were used. The statements concluded that the use of PhET in online learning activities received a very positive response from students, as indicated by their response and enthusiasm. Good response and reasonable confidence impact the evaluation results, which show $86 \%$ of students achieve completeness with a KKM value $=75$.
\end{abstract}

Keywords: science; online learning; virtual laboratory

\begin{abstract}
Abstrak
Kurangnya antusias peserta didik dalam pembelajaran IPA-Fisika secara daring di masa pandemi menuntut penulis untuk mencari terobosan kecil dalam proses pembelajaran materi Listrik Dinamis. Media PhET (Physical Education Technology) dapat digunakan sebagai media virtual alternatif untuk memandu peserta didik mempelajari konsep-konsep IPA secara hands on dan minds on dengan semangat. Artikle ini merupakan resume dari sebuah uji pembelajaran menggunakan laboratorium virtual pada materi listrik dinamis mata pelajaran IPA MTsN. Uji pembelajaran bertujuan melihat motivasi peserta didik terhadap pembelajaran dan mengukur hasil belajarnya. Dalam uji tersebut tersebut digunakan teknik observasi, wawancara dan tes. Hasil pengamatan menyimpulkan bahwa penggunaan media PhET dalan kegiatan pembelajaran daring mendapatkan tanggapan yang sangat positif dari peserta didik yang ditunjukkan dengan respon dan antusias mereka. Respon yang baik dan antusias yang baik berimbas kepada hasil belajar dengan Indikator 86\% peserta didik mencapai ketuntasan dengan nilai KKM = 75 .
\end{abstract}

Kata Kunci: Ilmu Pengetahuan Alam; motivasi belajar; media animasi 


\section{PENDAHULUAN}

Mata pelajaran IPA masih dianggap sebagai mata pelajaran yang sulit (Kurniawan, Astalini, \& Kurniawan, 2019; Anggraini, 2019; Yunarti, 2021). Salah satu penyebabnya karena konsep-konsep IPA bersifat abstrak. Salah satu contohnya ketika pada materi Listrik Dinamis di kelas IX. Konsep yang dipelajari pada topik ini adalah perilaku gerakan elektron yang berdampak terhadap arus listrik. Fenomena terebut sulit untuk diamati sehingga peserta didik kesulitan memahami konsep tersebut.

Salah satu indikator kesulitan peserta didik dalam mempelajari konsep tersebut adalah sebagian besar skor hasil tes kognitif belum melampaui KKM, terutama pada pokok bahasan Hukum Ohm dan rangkaian listrik.

Dalam pembelajaran sebelumnya di masa normal digunakan metode demonstrasi dan simulasi. Melalui pembelajaran seperti itu peserta didik pasif dan tidak termotivasi. Hal ini disebabkan karena pembelajaran yang kurang variatif sehingga kurang menarik bagi peserta didik.

Terlebih lagi di masa Pandemi Covid 19, pembelajaran semakin tidak terarah. Pembelajaran disajikan secara daring seluruhnya. Pada pembelajaran tersebut materi ajar disajikan dengan cara video meeting, membaca,tugas dan tes. Peserta didik tidak dapat melakukan kegiatan praktikum bersama guru secara langsung sehingga guru tidak dapat mendampingi peserta didik secara optmimal. Selain itu karena kemandirian belajar peserta didik belum baik menyebabkan kesulitan untuk memahami materi tersebut.
Untuk mengatasinya perlu dilakukan upaya untuk merubah penyajian pembelajaran agar pembelajaran lebih menyenangkan dan peserta didik lebih termotivasi untukk engikuti pembelajaran meskipun disajikan secara daring.

Salah satu cara yang dapat dilakukan adalah melalui pemanfaatan media pembelajaran yang sesuai dengan karakteristik materi pelajaran. Karena pembelajran disajikan secara daring maka media yang dipilih adalah ICT (information and communication technology) (Hanifah, Salsabila, Ghazali, \& Khoirunnisa, (2020).

Salah satu jenis aplikasi yang dapat digunakan adalah PhET virtual lab. PhET (Physics Education Technology) adalah sebuah perangkat lunak gratis dari University of Colorado. PhET merupakan software simulasi yang menyajikan simulasi interaktif pada materi-materi konsep IPA yang dapat digunakan untuk experimen maya (Sugiarti, S. (2017).

Alat simulasi ini dapat digunakan dengan mudah oleh peserta didik untuk mengeksplorasi konsep-konsep IPA pada semua tungkatan pendidikan. Simulasi dalam PhET bersifat interaktif dikemas layaknya laboratorium virtual sehingga siswa dapat melakukan eksplorasi. Perangkat lunak ini tersedia di http:/ / phet.colorado.edu.

Melalui media tersebut peserta didik dapat melakukan praktikum secara virtual interaktif. Virtul lab tersebut berbentuk artificial intelligence yang dapat menyajikan simulasi akurat mengenai fenomena saintifik. Melalui simulasi tersebut siswa dapat melihat bahkan mencoba melakukan experimen sendiri melibatkan variabel- 
variabel terkait. Melalui experimen tersebut peserta didik memperoleh informasi faktual yang dapat diproses dalam struktur kognisi untuk memahami fenomena abstrak yang sebenarnya terjadi. Kegiantan belajar bersifat hands on dan minds on tersebut memberikan informasi lebih banyak dan lebih kuat dalam ingatan mereka serta dapat meningkatkan motivasi belajar.

Penggunaan media aplikasi PhET sebagai media pembelajaran telah banyak diteliti dan menunjukkan persentasi keberhasilan yang signifikan. Diantaranya penelitian yang dilakukan oleh Nurhayati, dkk yang dikutip oleh Rozi Saputra, dkk. Hasil penelitian menyatakan bahwa hasil belajar peserta didik yang diajarkan dengan metode eksperimen berbantuan media PhET lebih baik dari pada hasil belajar peserta didik dengan menggunakan metode konvensional (Saputra, 2020). Hasil experimen pengaruh penerapan PhET pada motivasi dan aktifitas belajar pada mata pelajaran Kimia konsep kelarutan dan hasil kali kelarutan di SMAN 7 Banda Aceh menunjukkan terdapat perbedaan signifikan antara kelas yang menggunakan PhEt dengan yang tidak (Marlinda, Halim, \& Maulana, 20016). Hasil penelitian deskrptif pada materi gelombang di kelas VII Sekolah Menengah Internasional (International Junior High School) di Bandung menunjukkan. Hasil penelitian menunjukkan adanya peningkatan hasil belajar baik pada spek kognitif maupun pada aspek kondisi belajar laboratorium (Maulidah \& Prima, 2018). Hasil penelitian metanalisis terhadap 30 artikle mengenai penggunaan laboratorium virtual menyumpukan bahwa penggunaan laboratorium virtual sebagai media dapat digunakan untk mengatasi masalah-masalah pembelajaran pada peserta didik. Berdasarkan metaanalisis tersebut peneliti merekomendasikan agar guru meningkatkan kompetensi dalam penggunaan laboratorium virtual. Kedua laboratorium virtual dapat dijadikan salah satu alternatif solusi untuk mengatasi kendala dalam proses pembelajaran selama pandemi Covid-19 (Zaturrahmi, Festiyed, \& Ellizar, 2020). Sebuah quasi experiment pada siswa STEM di Baybay City Senior High School pada mata pelajaran Fisika ditemukan fakta rendahnya perbedaan hasil belajar kognitif pada kelompok peserta didik yang diberi kesempatan menggunakan PhET. Peneliti memperdiksi bahwa kemungkinan besar peserta didik hanya tertarik pada bermain experiment menggunakan PhET namun tidak terlalu memperhatikan substansi materinya (Ananias N. Yunzal \& Casinillo, 2020).

Hasil-hasil penelitian di atas pada umumnya menegaskan adanya dampak positif terhadap penguasaan peserta didik terhadap hasil belajar aspek kognitif. Berdasarkan hasil penelitian tersebut penulis tertarik untuk mencoba melakukan uji pembelajaran menggunakan PhET.

Artikel ini adalah resume hasil uji pembelajaran menggunakan PhET pada sebuah pembelajaran konsep listrik dinamis di sebuah kelas. Pada uji coba tersebut dilakukan pembelajaran dengan metode eksperimen sebagai metode utama menggunakan aplikasi Phet. Uji pembelajaran tersebut dilakukan untuk menjelaskan dampak aplikasi Phet terhadap motivasi dan 
penguasaan konsep IPA pada materi listrik dinamis.

\section{METODE}

Uji coba pembelajaran dilakukan di kelas VII MTs di Kelas IX B yang terdiri dari 37 peserta. Uji coba dilaksanakan pada tangal 26 Oktober 2020.

Peneliti melakukan pembelajaran menggunakan aplikasi PhET pada pembelajaran materi listrik dinamis, kemudian dibantu oleh kolega melihat dan merekam proses dan hasil pembelajarannya. Variabel yang diamati adalah motivasi para peserta didik hasil belajar aspek kognitifnya.

Untuk mengumpulkan data mengenai motivasi peserta didik digunakan teknik obsertvasi dan wawancara, sedangkan untuk mengukur hasil belajar digunakan soal. Data yang terkumpul dilah dengan 2 teknik. Data kuantitatif dalam bentuk hasil belajar diolah menggunakan statistik deskriptif, sedangkan data kualitatif diolah dengan teknik interpretif.

Pembelajaran dilakukan melalui tiga tahap berikut:

Tahap Perencanaan

a. Penyusunan RPP.

b. Pemilihan aplikasi PhET

c. Pembuatan lembar kerja siswa.

Tahap Pelaksanaan

a. Guru melakukan demontrasi praktikum menggunakan media PhET

b. Peserta didik mengamati, mengisi dan mengisi LKPD

c. Diskusi dan tanya jawab.

d. Peserta didik bersama guru membuat kesimpulan

e. Peserta didik mengirim foto LKPD kepada guru f. Guru melakukan penilaian hasi belajar dengan menggunakan media wordwall.

\section{HASIL DAN PEMBAHASAN}

Kegiatan pembelajaran eksperimen Listrik Dinamis pada materi rangkaian listrik dilakukan oleh peserta didik secara mandiri dalam kelompok kecil menggunakan PC atau laptop. Sebelumnya telah diberikan kepada setiap kelompok Lembar Kerja Peserta Didik (LKPD) berupa file word yang sudah diberikan satu hari sebelum pembelajaran dengan harapan peserta didik dapat mencetak file ataupun menulis kembali di buku catatan mereka.

Pada LKPD disajikan lakngkahlangkah membuka aplikasi, mengunduh dan melakukan eksperimen mandiri. Pada LKPD peserta didik dipandu untuk seting variabel dan melakukan eksperimen untuk mengamati besar arus pada rangkauan terbuka dan tertutup, rangkaian seri dan parallel dan dampak penambahan dan pegurangan sumber tegangan terhadap arus baik seri maupun parallel.

Beberapa rangkaian yang ditunjukkan kepada peserta didik adalah sebagai berikut. 


\section{Wawasan:}

Jurnal Kediklatan Balai Diklat Keagamaan Jakarta

PISSN: 2548-9232; EISSN: 2775-3573

Volume 2 Nomor 1 Tahun 2021: 32-39

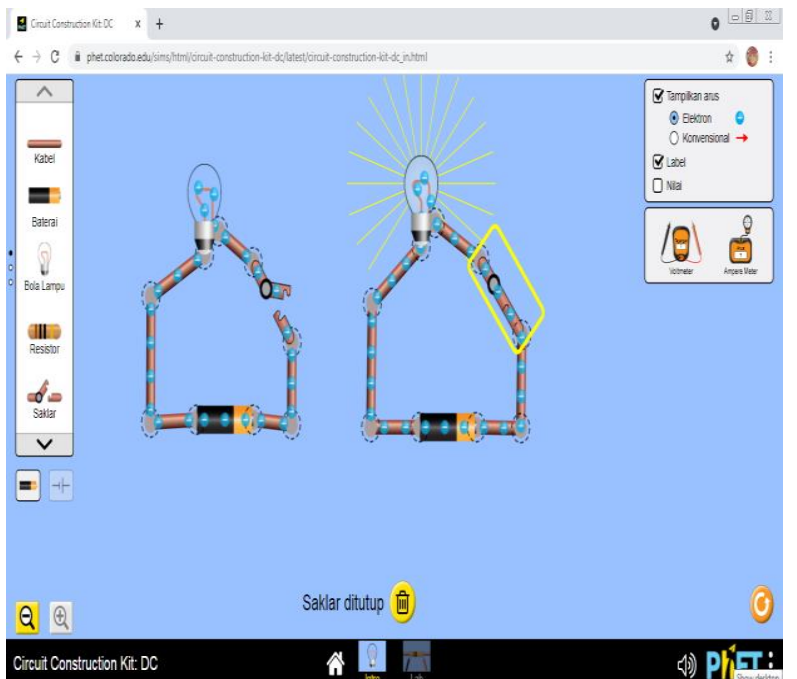

Gambar 1 Rangkain Terbuka \&Tertutup

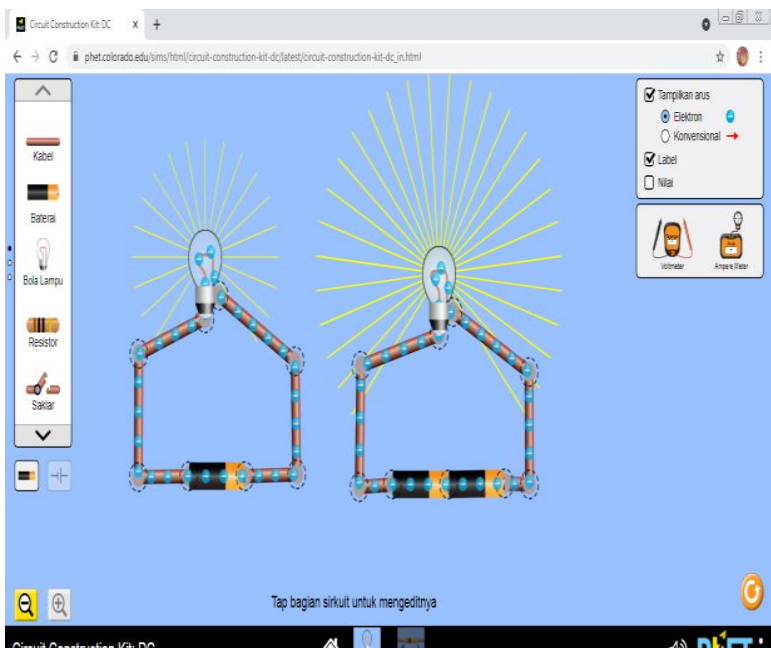

Gambar 2 Hubungan Beda Potensial \& Kuat Arus Listrik

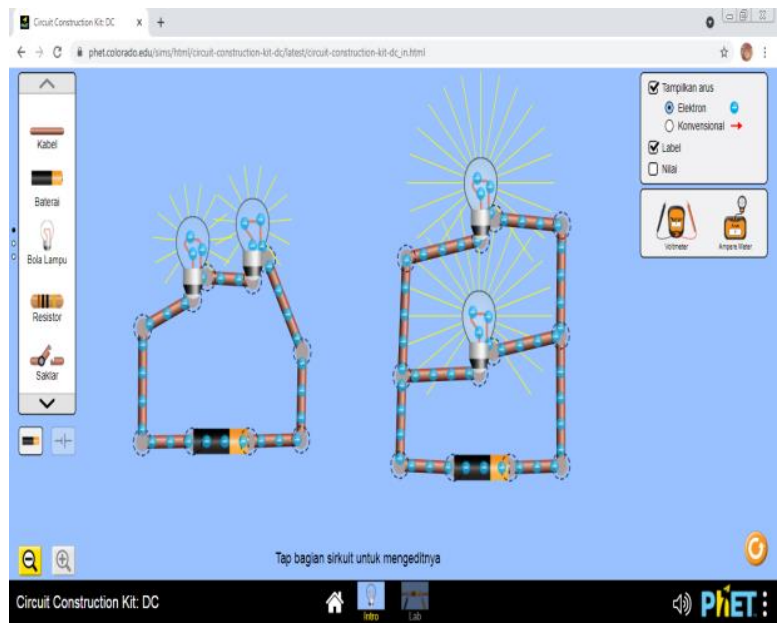

Gambar 3 Rangkain Seri \& Paralel

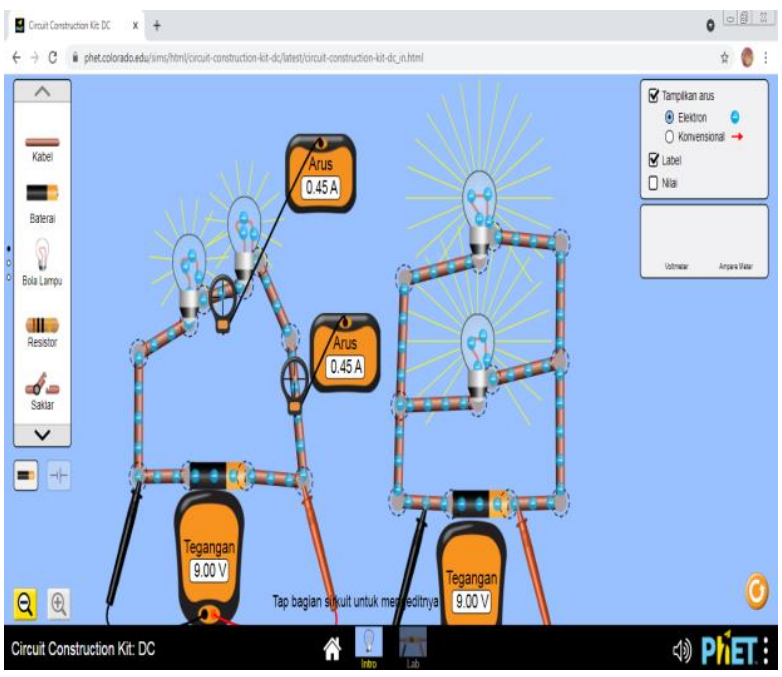

Gambar 4 Nilai Kuat Arus Rangkaian Seri

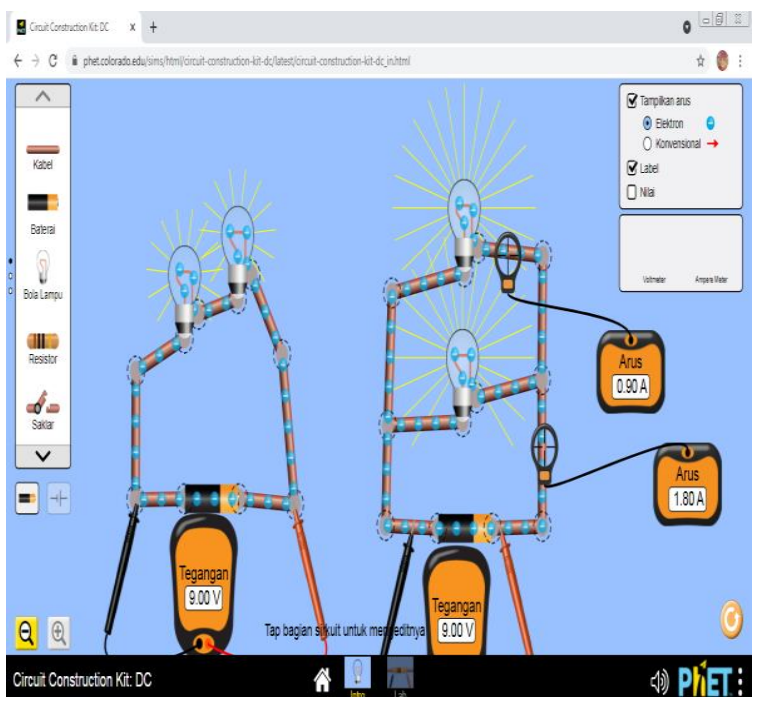

Gambar 5 Nilai Kuat Arus Rangkaian Paralel

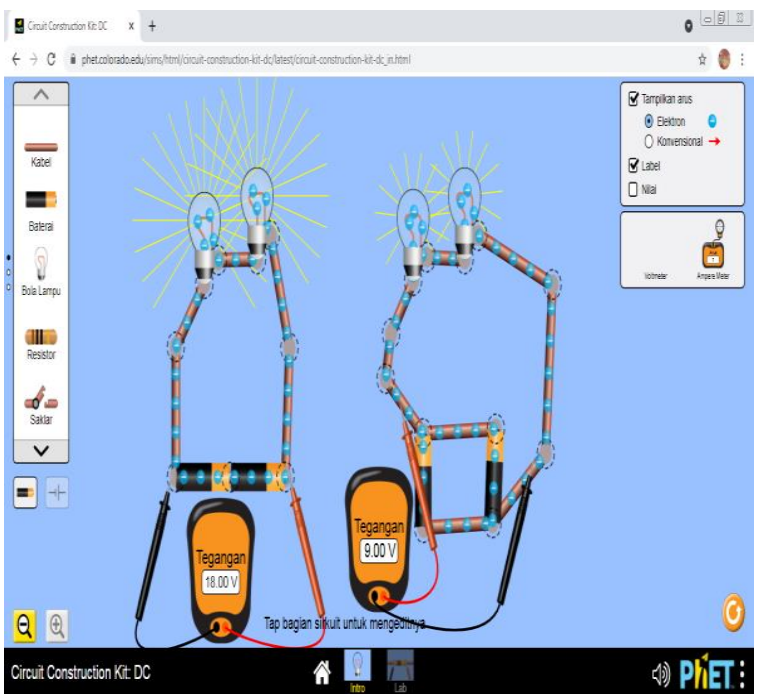

Gambar 6 Rangkaian Sumber Tegangan 
Setelah selesai mendemontrasikan beberapa rangkain listrik, penulis memberi kesempatan siswa untuk mengirimkan foto LKPD mereka untuk dikirim kepada penulis melalui WA dan penulis memberikan link. evaluasi pembelajaran dengan media wordwall.

Hasil belajar peserta didik setelah menggunakan pembelajaran dengan menggunakan media PhET terlihat dari grafik berikut.

\section{Correct or incorrect by question}

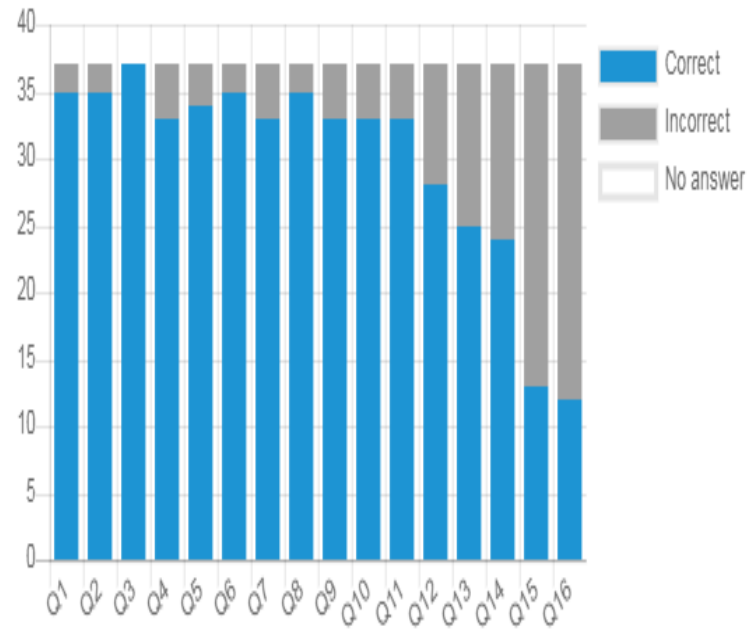

Grafik 1 Distribusi Jawaban Peserta Didik

Berdasarkan grafik distribusi jawaban peserta didik diatas, dapat dilihat bahwa semua peserta didik menjawab semua soal yang diberikan. Dari 16 soal yang diberikan rata-rata peserta didik dapat menjawab dengan benar. Hanya pada soal nomor 15 dan 16 sebagian besar siswa belum menjawab dengan benar.

Perolehan nilai peserta didik disajikan pada grafik berikut:

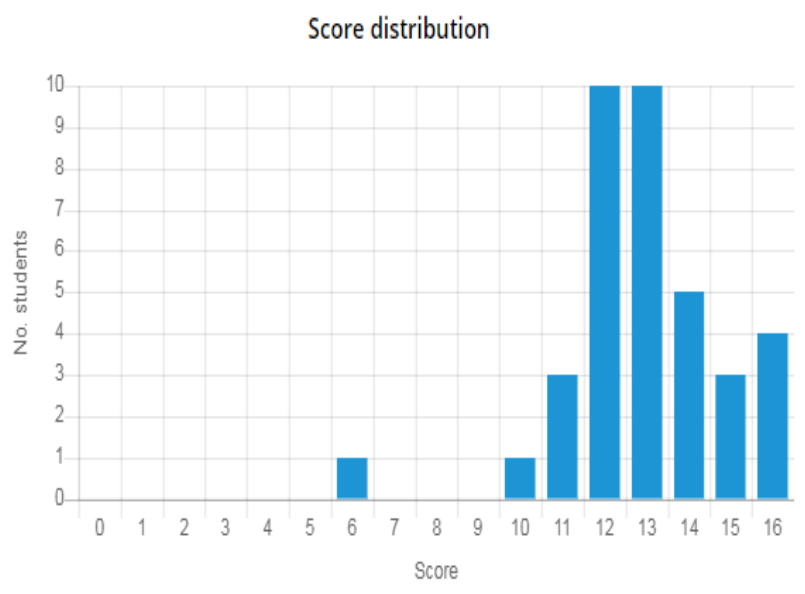

Grafik 2 Distribusi Nilai Peserta Didik

Grafik 2 memperlihatkan bahwa dari seluruh siswa yang mengerjakan soal evaluasi rata-rata menjawab sebanyak 12-13 soal dengan benar. Sehingga rata-rata dalam satu kelas memperoleh nilai berkisar 75 - 81. Hal ini menunjukkan preastasi yang luar biasa dibandingkan pembelajaran sebelumnya.

Penggunaan media PhET dalam kegiatan praktikum pada masa pandemi sangat efektif dan memberikan hasil nyata. Biasanya pada mata pelajaran IPA-Fisika peserta didik sering mengalami kesulitan yang ditunjukkan dengan hasil belajar masih banyak peserta didik yang memperoleh nilai dibawah KKM, hampir 50\% peserta didik tidak tuntas. Namun dengan menggunakan media PhET hasil belajar peserta didik menunjukkan hasil yang optimal. Berdasarkan data perolehan nilai pada grafik 2 terdapat kurang lebih 86\% peserta didik mencapai ketuntasan dalam pembelajaran. Hal ini menunjukkan bahwa penggunaan media PhET dalam pembelajaran sangat efektif digunakan. 
Keberhasilan pencapaian hasil belajar peserta didik disebabkan antusias siswa dalam mengikuti proses pembelajaran serta link PhET yang mudah diakses. Antusias peserta didik ditunjukkan pada kolom chat googlemeet. Sebagian besar peserta didik mengatakan senang dengan pembelajaran menggunakan media animasi PhET. Salah satu dari peserta didik menyampaikan kesannya: "Pembelajaran hari ini sangat unik karena kita diberi tahu salah satu aplikasi yang unik untuk menggambar rangkaian seri dan pararel dengan aplikasi PhET, bu Yuni tidak perlu menulis di papan tulis hanya tinggal menggunakan computer untuk menggambar pararel dengan mudah aplikasi phet sangat mudah digambar".

Namun jika diperhatikan masih terdapat beberapa peserta didik yang memperoleh nilai dibawah KKM, hal ini terjadi karena terdapat beberapa kendala yang dihadapi diantaranya:

a. Semangat peserta didik untuk segera bergabung di Googlemeet masih kurang sehingga kurang fokus dalam mendengarkan penjelasan dari guru karena smpat terkambat bergabung di kelas googlemeet.

b. Peserta didik belum sepenuhnya bisa menggunakan mediat PhET sehingga belum dapat diberlakukan praktikum IPA secara virtual

c. Penggunaan media PhET belum dapat dilakukan secara optimal oleh peserta didik karena terkendala kuota internet bagai beberapa peserta didik
Dengan memperhatikan antusias peserta didik dalam mengikuti kegiatan praktikum virtual, menunjukkan peserta didik sangat termotivasi dan semangat untuk belajar maka kegiatan pembelajaran tersebut bisa dikembangkan pada materi yang berbeda.

\section{KESIMPULAN}

Penggunaan media PhET pada kegiatan praktikum virtual cukup efektif dan optimal. Media PhET dapat membuat peserta senang dalam mengikuti pembelajaran. Hal ini merupakan salah satu indikator motivasi dalam pembelajaran. Disamping itu dapat juga meningkatkan hasil belajar yang dibuktikan peserta didik yang mendapat nilai sama dengan atau lebih dari KKM sebanyak $86 \%$ dari jumlah siswa. Hal tersebut menunjukkan bahwa media PhET dapat dijadikan alternatif pilihan dari media lain yang mungkin ada.

Kegiatan pembelajaran ini dapat dikembangkan juga untuk memunculkan gagasan atau ide dari guru untuk menggunakan media yang lainnya pada materi yang berbeda dalam rangka memperbaiki proses pembelajaran daring.

Berdasarkan kesimpulan tersebut peneliti merekomendasikan untuk menggunakan aplikasi Phet sebagai alternatif media yang dapat digunakan untuk menunjang pembelajaran IPA berbasis hands on dan minds on. Terlebih lagi pada jarak jauh online.

\section{DAFTAR PUSTAKA}


Ananias N. Yunzal, J., \& Casinillo, L. F. (2020). Effect of Physics Education Technology (PhET) Simulations: Evidence from STEM Students' Performance. Journal of Education Research and Evaluation, 221-226.

Anggraini, L. (2019). KORELASI ANTARA PERCAYA DIRI DENGAN SIKAP SISWA TERHADAP MATA PELAJARAN IPA DI SMP SE-KECAMATAN MESTONG (Doctoral dissertation, Univrsitas Jambi).

Hanifah, H., Salsabila, U. H., Ghazali, I., \& Khoirunnisa, N. (2020). Strategi Alternatif Pembelajaran Daring Mahasiswa Pendidikan Agama Islam Pada Masa Pandemi Covid-19. JURNAL EDUSCIENCE, 7(2), 68-77.

Kurniawan, D. A., Astalini, A., \& Kurniawan, N. (2019). Analisis Sikap Siswa SMP terhadap Mata Pelajaran IPA. Lentera Pendidikan: Jurnal Ilmu Tarbiyah dan Keguruan, 22(2), 323-334.

Marlinda, Halim, A., \& Maulana, I. (20016). Perbandingan Penggunaan Media Virtual Lab Simulas PhET (Physiacal Education Technology dengan Metode Experimen Terhadap Motivasi dan Aktivitas Belajar Peserta Didika pada Materi Kelarutan dan Hasil Kali Kelarutan . Jurnal Pendidikan Sain Indonesia, 6982.

Maulidah, S. S., \& Prima, E. C. (2018). Using Physics Education Technology as Virtual Laboratory in Learning Waves and Sounds. Journal of Science Learning, 116-121.

Saputra, R. (2020). Pengaruh Penggunaan Media Simulasi Phet (Physics Education Technology) Terhadap Hasil Belajar Fisika. Jurnal Pijar MIPA, 110-115.

Sugiarti, S. (2017). PEMBELAJARAN BERBANTUAN SIMULASI PhET DALAM MEMBANGUN PEMAHAMAN KONSEP FISIKA SISWA POKOK BAHASAN ALAT OPTIK. Jurnal Dosen Universitas PGRI Palembang.

Yunarti, N. (2021). Analisa Kesulitan Dalam Pembelajaran IPA Pada Siswa SMP Negeri 1 Rambang. Jurnal Educatio FKIP UNMA, 7(4), 1745-1749.

Zaturrahmi, Festiyed, \& Ellizar. (2020). THE UTILIZATION OF VIRTUAL LABORATORY IN LEARNING: A META-ANALYSIS. Indonesian Journal Of Science and Mathematics Education, 228-236. 